\title{
EREBEA
}

Revista de Humanidades

y Ciencias Sociales

Núm. 1 (2011), pp. 83-102

ISSN: 0214-0691

\section{Las Colecciones de Sermones de Juan Gil de Zamora (O. F. M.) (CA. I 24I-CA. I 3 I 8): EL LIBER SERMONUM Y EL BREVILOQUIUM SERMONUM VIRTUTUM ET VITIORUM}

Fernando Lillo Redonet

IES San Tomé de Freixeiro (Vigo)

RESUMEN

En este artículo damos a conocer la existencia de dos colecciones de sermones atribuidas a Juan Gil de Zamora (OFM): el Liber sermonum, compuesto por 70 sermones variados, y el Breuiloquium sermonum uirtutum et uitiorum, integrado por 15, dedicándose cada uno de ellos a un vicio o una virtud. La estructura general del Liber sermonum está también estudiada centrándose en siete sermones pertenecientes al grupo de los sermones temporales, y comparándolo con las reglas de las Artes praedicandi.

\section{Palabras Clave}

Juan Gil de Zamora, Liber sermonum, Breuiloquium sermonum uirtutum et uitiorum.

Fecha de recepción: 11 de febrero de 2011

Fecha de aceptación: 1 de marzo de 2011

\section{Abstract}

The existence of two sermon collections attributed to Juan Gil de Zamora (OFM) is established in this article: the Liber sermonum, made up of 70 varied sermons, and the Breuiloquium sermonum uirtutum et uitiorum, that consist of 15 sermons, each one describing different vices or virtues. The Liber sermonum' general structure is also studied by focusing on seven sermons belonging to the sermones temporales group, and comparing it with the Artes praedicandi rules.

\section{KeYwords}

Juan Gil de Zamora, Liber sermonum, Breuiloquium sermonum uirtutum et uitiorum. 



\section{INTRODUCCIÓN}

Los sermones de Juan Gil de Zamora son, sin duda, menos conocidos que el resto de su prolífica obra ${ }^{1}$. En este artículo presento los datos extraídos del análisis del códice 414 de la Biblioteca del Sacro Convento di San Francesco, fondo antico della Biblioteca Comunale que llevan a establecer la existencia de dos colecciones de sermones atribuidos a Juan Gil de Zamora: una obra mayor de 70 sermones que se llamaría Liber sermonum y otra menor de 15 sermones bajo el título de Breuiloquium sermonum uirtutum et uitiorum. De la obra mayor he editado una selección de siete sermones en el no 1 de la colección Ihoannes Aegidii Zamorensis opera omnia dirigida por la Dra. Cándida Ferrero Hernández en el seno del Instituto de Estudios Zamoranos "Florián de Ocampo"2. Esta edición es la base de las conclusiones parciales que muestro sobre el modo de componer sermones de Juan Gil.

La predicación era una preocupación de la orden franciscana y Juan Gil compuso un legendario para uso de los frailes de su provincia titulado Legende sanctorum et festiuitatum aliarum de quibus ecclesia sollempnizat conservado en un manuscrito de Londres (British Library. Mss. Add. 41070) que está siendo editado por los Dres. J. C. Martin y E. Otero ${ }^{3}$. Sus recientes editores, teniendo en cuenta que la obra es posterior a la Historia naturalis, cuya redacción establecen entre 1279 y 1289, toman estas fechas como un terminus post quem. Con seguridad Juan Gil compuso su Liber sermonum, del que daremos cuenta a continuación, con anterioridad al legendario, puesto que aparece citado en este ${ }^{4}$. El Liber ser-

1 Para una puesta al día de la vida y obra de Juan Gil de Zamora véase C. Ferrero Hernández, Liber contra venena et animalia venenosa de Juan Gil de Zamora, Barcelona, Reial Acadèmia de Bones Lletres, 2009, pp. 19-39.

2 F. Lillo Redonet, Sermonario de Juan Gil de Zamora. Estudio preliminar, edición, traducción y comentario de siete de sus sermones. Ihoannes Aegidii Zamorensis opera omnia I, Zamora, Instituto de Estudios Zamoranos, en prensa. Esta edición, base del presente artículo, mejora y corrige mis trabajos anteriores sobre el sermonario: F. Lillo Redonet, "El sermonario inédito de Juan Gil de Zamora a la luz de las Artes praedicandi", Actas del I Congreso Nacional de Latin Medieval, diciembre, 1993, M. Pérez González (ed.), León, 1995, pp. 14-38 y "El códice 414 de la Biblioteca de Asís y los sermones de Juan Gil de Zamora", AIA 58, 1998, pp. 145-172.

3 J. C. Martín y E. Otero Pereira, Juan Gil de Zamora (O. F. M.), Legende sanctorum et festiuitatum aliarum de quibus ecclesia sollempnizat. Edición crítica, introducción, traducción y notas, Zamora, 2011, en prensa. Agradezco a los editores el permitirme consultar su trabajo antes de su publicación definitiva.

4 Requirebatur ergo ad tantum saltum faciendum ut haberet agilitatem humilitatis, gracilita- 
monum, cuya fecha exacta de composición desconocemos, es también anterior al Breuiloquium sermonum uirtutum et uitiorum, ya que se hace referencia a él en la compilación menor.

2. El códice 4i 4 de la Biblioteca del Sacro Convento di San FranCESCo, Fondo antico della Biblioteca Comunale'5 Y los SERmones DE JuAN Gil de Zamora

La primera descripción del códice y su contenido se debe al antiguo catálogo de la biblioteca del convento de San Francisco de la ciudad de Asís compuesto en el año 1381 y editado por Leto Alessandri ${ }^{6}$ :

Biblioteca secreta S. XVII.-Sermones fratris egidii hispani ord. minorum pro aliquibus solempnitatibus spettabilibus. Et commune sanctorum. Cum postivus (sic.). Cuius principium est: Philosophia est diuinarum humanarumque speculatio. Finis vero: de auaritia.272. In quo libro omnes quaterni sunt XII. N.

La descripción resulta insuficiente y no da los datos precisos. La que proporciona Mazzatinti ${ }^{7}$ es algo mejor pero igualmente confusa:

414: Breuiloquium de uitiis et uirtutibus (titolo del sec. scorso): Philosophia est diuinarum/seculorum amen. (fol. 1-75) -Summa sermonum: Post sermones temporales/gaudium plenum ad quod... etc. (fol 77-256) Segue la tavola delle rubriche dei sermoni.

Memb. sec XIV 180x125 mm. ff. 257 scr. a due col. Varie pagine sono bianche. In fine "in isto libro omnes quaterni sunt XXV". La tavola che é pure in fine ha il titolo: Sermones dominicales et festivi communes et breuiloquium fratris Egidii Yspani ministri fratrum minorum Portugalie.

$\mathrm{Cenci}^{8}$ ofrece la descripción del códice más reciente y en la ficha de Internet correspondiente figuran los siguientes datos:

Membr.; fascicoli legati; 1301-1330 desumibile; cc. 259; (carte bianche: $98 \mathrm{v}-100 \mathrm{v}, 256 \mathrm{v}-257 \mathrm{r}, 258 \mathrm{r}-259 \mathrm{v}) ; \mathrm{mm} 180$ x 125 (c. 1). Fascico-

\footnotetext{
tem paupertatis, uigorositatem castitatis, sicut in opere sermonum nostrorum de ascensione plenius est expressum. (fol. 69v); (sobre la fiesta de Juan Bautista) In preconio tanti festi multa inueniuntur in opere sermonum nostrorum (fol. 246r).

5 El códice está disponible para su consulta en Internet en http://88.48.84.154/bbw/jsp/volumes/.

6 L. Alessandri, Inventario dell'antica biblioteca del S. Convento di S. Francesco in Assisi compilato nel 1381, Assisi, 1906, p.132.

7 G. Mazzatinti, Inventario dei manoscritti della biblioteche d'Italia.IV, Forli, Casa editrice Luigi Bordandini 1894.

8 C. Cenci, Bibliotheca manuscripta ad sacrum conventum Assisiensem, vol. 1, Assisi, 1981, pp. 364-365, nr. 699.
} 
lazione: 25 quaterni, vd. c. $257 \mathrm{v}$, ma o mancano il 9 e il 10 o la notizia è errata; Segnatura dei fascicoli: "quaternatura assisiensis"; cfr. CENCI, Bibliotheca, I, p. 364. Disposizione del testo: a due colonne; cfr. CENCI, Bibliotheca, I, p. 364. Scrittura e mani: scrittura del XIV secolo; cfr. CENCI, Bibliotheca, I, p. 364. Legatura: 1801-1900, cosiddetta «ligatura assisiensis»; cfr. CENCI, Bibliotheca, I, p. 364. Storia del manoscritto: sul dorso sta scritto «Sermones SSM»; a c. 3r tassello cartaceo; a c. 159r «fr. Deotacomandus ... de conventu pro omnibus infirmis usque ad ... pro illis duobus fratribus forensibus de provincia s. Antonij»; a c. $257 \mathrm{v}$ «In isto libro: omnes quaterni. sunt XXV»; a c. 259v la mano di Giovanni di Iolo «Sermones dominicales. festivi. comunes. et breviloquium fratri(s) iohannis egidij yspani. ministri fratrum minorum portugalie» Altra relazione di D.E. identificato: Giovanni : di Iolo. (cc. 1v) Titolo aggiunto: Formularius dictaminis epistolarum (cc. 3r-75v) Autore identificato: Johannes Aegidius : de Zamora (SBN). Titolo aggiunto: Sermones dominicales Testo inc.: Philosophia est divinarum humanarumque rerum (c. 3r) (cc. 77r-98r) Autore identificato: Johannes Aegidius : de Zamora (SBN). Titolo aggiunto: Sermones mariales Testo inc.: Post sermones temporales (c. 77r) (cc. 101r166r) Titolo aggiunto: Sermones de sanctis Testo inc.: De sollempnitatibus et sollempnia (c. 101r) (cc. 166r-216r) Autore identificato: Johannes Aegidius : de Zamora (SBN). Titolo presente: Opus sermonum copiosum (c. 216r) Testo inc.: Iusta conditionem materiae sunt (c. 166r) (cc. 217r255r) Autore identificato: Johannes Aegidius : de Zamora (SBN). Titolo presente: Breviloquium sermonum virtutum et vitiorum (c. 255r) Testo inc.: Super omnia caritatem (c. 217r) Osservazioni: a c. $257 \mathrm{v}$ si trova la tabella dei sermoni (cc. 255v-256r) Testo inc.: Ave gratia plena (c. 255v) expl.: Si vis inmitari virginem gloriosam (c. 256r).

Tras nuestro análisis personal concluimos que el códice contiene dos obras de Juan Gil de Zamora. La primera que desde Lucas Wadding ${ }^{9}$ y Sbaralea ${ }^{10}$ hasta M. de Castro $^{11}$ y K. Reinhardt ${ }^{12}$ se denominaba erróneamente Sermones sanctorum ocupa los folios 3r-216r. La segunda, llamada Breuiloquium sermonum virtutum et uitiorum, ocupa los folios $217 \mathrm{r}-255 \mathrm{r}$.

La primera obra es una colección de 70 sermones de tema variado ${ }^{13}$ según las rúbricas de los asuntos que aparecen al final del manuscrito: De aduentu

9 L. Wadding, Scriptores O.M., Roma 1650, pp.188-189.

10 I. Sbaralea, Supplementum et castigatio ad Scriptores trium ordinum S. Francisci II, Roma, 1921, pp.25-27.

11 M. de Castro, Fr.Juan Gil de Zamora. De preconiis Hispanie. Estudio preliminar y edición critica, Madrid 1955.

12 K. Reinhardt, Die biblischen Autoren Spaniens bis zum Konzil von Trient, Salamanca 1976, pp.121-124.

13 Los incipit y explicit de cada sermón aparecen en mi edición parcial del sermonario citada en la nota 1. 
Christi (sermones 1-5), De Natiuitate Christi (6-7), De Circumcisione (8-9), De Epiphania siue Apparitione (10-12), De Septuagesima et Quadragesima (13-15), De Ramis Palmarum (16-17), De Resurrectione (18-19), De Ascensione Christi (20-21), De Pentecoste siue Emissione Spiritus Sancti (22-24), De Natiuitate Virginis (25-26), De Anuntiatione (27-28), De Purificatione (29-30), De Assumptione (31-32), De angelis ${ }^{14}$, De festo crucis, De festo unius apostoli (33-34), De festo plurimum apostolorum (35-37), De euangelistis (38-39), De festo unius martiris (40-41), De festo martirum plurimorum (42-43), De confessore pontifice (44-46), De doctoribus (47-48), De confessore simplici (49-50), De uirginibus (51-53), Pro curiis magnatorum (54-55), Pro conventibus religiosorum (56-57), Pro Sinodis (58-59), Pro missis nouis seu sacerdotibus nouis (60-61), Pro consecrationibus ecclesiarum (62-63), Pro consecratione et uisitatione monialium (64-65), Pro tempestate pluuie ut(sic.) siccitate uel alterius tribulationis (66-67), Pro obsequis mortuorum (68-70).

La colección está precedida de un proemio dedicatorio que ocupa los folios 3r$4 \mathrm{v}$. A cada bloque de sermones, compuesto normalmente de dos o tres sermones sobre el mismo asunto, le precede una transición general de extensión variable que suele invitar al lector a la meditación del asunto tratado. La variedad de asuntos nos anima a pensar que el título con el que se aludía a esta obra no responde a su contenido. Si se llamó Sermones sanctorum su nombre sólo daría cuenta de un asunto de los muchos que trata. Además, a través de los testimonios del propio autor no podemos inferir tal título sino otro de tema más general.

Así en el explicit de la obra en este mismo manuscrito (fol. 215v-216r) dice (el subrayado es nuestro):

Explicit opus sermonum copiosum editum a fratre Ihoanne Egidii yspano de ordine fratrum minorum militantium sub habitu beati Francisci signiferi stigmatum Ihesu Christi.

En su obra Breuiloquium sermonum uirtutum et uitiorum de este mismo manuscrito dice al terminar la dedicatoria al obispo Martín (fol. 217r):

... in sermonibus quidem nostris operis copiosi de omni materia sufficientissime pertractaui.

En el manuscrito 2763 de la Biblioteca Nacional de Madrid se lee:

Explicit XXIII liber Historie Canonice ac ciuilis editus a fratre Iohanne Egidii de ordine fratrum minorum, natione Hispanus, de regno legionen-

14 Las rúbricas finales aluden a sermones De angelis y De festo crucis que no aparecen en el manuscrito. 
si, et de Ciuitate Zamorensi, que apud antiquos fuit Numantia apellata. In libro nostro sermonum qui datur copiosus ad omnem materiam et in libro meditationum et orationum plurima inueniuntur que redunt commendabiles multas personas canonicas et ciuiles...

En consecuencia es posible que su título hubiese sido Liber sermonum copiosus o simplemente Liber sermonum. Con todo, lo que se demuestra es la amplitud de asuntos del libro calificado como copiosus.

La segunda obra de este códice tiene un título claro en el explicit (255r):

Explicit Breuiloquium sermonum uirtutum et uitiorum in congruitatem temporum et locorum.

El Breuiloquium sermonum uirtutum et uitiorum consta de una pequeña dedicatoria, apenas el recto del folio 217, y de 15 sermones monográficos sobre distintos vicios y virtudes: De caritate, De humilitate, De pace, De sobrietate, De castitate, De iustitia, De misericordia, De patientia, De oratione, De odio, De superbia, De ira, De ebrietate, De luxuria, De auaritia.

La dedicatoria atribuye la obra a Gil de Zamora que la dedica a su amigo don Martín ( «m» en el códice), obispo de León. M. de Castro identifica, con probabilidad, a ese don Martín con don Martín Fernández, 1254-1289. El Breuiloquium estaría, por tanto, compuesto antes de 1289. Respecto a la cronología de la primera obra de sermones, nada nos dice la dedicatoria, en la que se dirige a un obispo, cuyo nombre no aparece. Puede referirse al mismo del Breuiloquium o no. El que las dos obras estén juntas puede obedecer tanto a pertenecer a un mismo destinatario como a tener en común el hecho de que las dos son colecciones de sermones. En todo caso los explicit las independizan.

El Liber sermonum habría sido compuesto antes de la Historia canonica ac civilis, del Breuiloquium y también de las Legende sanctorum como ya hemos dicho.

3. Estructura general de los Sermones del Liber sermonum de Juan GiL De Zamora

El análisis que realizamos de la estructura de los sermones del Liber sermonum se ha hecho teniendo como base los siete sermones por mi editados que son los primeros de cada uno de los siete primeros asuntos de los que se compone la colección:

- Sermón I (no 1 de la colección) (4v-8r) (De aduentu Christi): Visitabo uos et suscitabo super uos uerbum meum bonum.

- Sermón II (no 6) (17v-21r) (De Natiuitate Christi): Gaudium magnum erit omni populo quia natus est nobis hodie Salvator. 
- Sermón III (no 8) (25v-28v) (De Circumcisione): Vocauit Abraham nomen filii sui Isaac et circumcidit eum ocatuo die.

- Sermón IV (no 10) (31v-34v) (De Epiphania): Venite et uidete opera Domini que posuit prodigia super terram.

- Sermón V (no 13) (40r-42v) (De Quadragesima): Tempus flendi et tempus ridendi.

- Sermón VI (no 16) (49v-51r) (De Ramis Palmarum): Flores apparuerunt in terra nostra. Tempus putationis aduenit.

- Sermón VII (no 18) (54r-56v) (De resurrectione): Si consurrexistis cum Christo que sursum sunt querite.

La terminología retórica la hemos obtenido de la que ofrecen algunas de las Artes predicandi más o menos contemporáneas a los sermones de Gil de Zamora. No podemos saber si nuestro autor consultó para realizar sus sermones alguna de las que hemos utilizado, sin embargo las consideramos importantes por ser una de las fuentes para el estudio de las técnicas literarias de la Edad Media. A partir de ellas se extraen principios teóricos que pueden aplicarse al estudio concreto de cada texto. Conviene, no obstante, observar el inconveniente que apunta Charland ${ }^{15}$ :

"ils ont l'incurable défaut d'arriver après les chefs-d'oeuvre, loin de les engendrer, afin de fixer dans un code une création dont la première loi est de ne point relever d'un code".

Nosotros aplicamos a los sermones editados las conclusiones de Charland, extraídas de las artes de Roberto de Basevorn y de Thomas Waleys, añadiendo testimonios del Ars concionandi del Pseudo-Buenaventura ${ }^{16}$. Este tratado erróneamente atribuido a Buenaventura nos interesa por circular entre los franciscanos y por su interés en los modos de dilatar el sermón.

Antes de analizar la estructura general de los sermones conviene hablar sobre las transiciones a cada bloque de sermones orientadas a invitar a meditar sobre el tema propuesto exponiendo las excelencias del mismo y el placer que se derivará de su contemplación. La fórmula transitoria utilizada por Juan Gil es por lo general "Post sermones (nombre del bloque que acaba de tratarse) procedendum est ad sermones (nombre del bloque que se va a tratar), aunque pueden existir variantes.

Estas transiciones son de variada extensión, siendo las más largas las que nosotros hemos editado y que corresponden a los primeros bloques de sermones de la colección. En otras ocasiones la brevedad es extrema y se reduce a la mera fórmula de transición ya aludida.

15 Th. M. Charland, Artes praedicandi. Contribution à l'histoire de la Rhétorique au Moyen Age, Publications de l'Institut d'études médievales d'Ottawa, 1936, p. 7.

16 S. Bonaventurae opera omnia. Tomus IX.Quarracchi 1901, pp. 8-21. 
La primera transición se encuentra precediendo al bloque de sermones relativos a la Navidad. Sin embargo, su contenido no se refiere sólo a esta festividad sino que abarca en sus apreciaciones hasta la Cuaresma, introduciendo un bloque más amplio, aunque luego cada bloque tenga su propia transición. En esta transición se explica la finalidad y el provecho a nuestro favor de los hechos de la vida de Jesucristo desde la Navidad hasta la Cuaresma.

Juan Gil no cita las fuentes que utiliza para componer estas transiciones, pero hemos localizado algunas que evidencian que nuestro autor se muestra como un mero compilador. En la primera el texto está inspirado en Adamo de Persenia, Epistulae. PL 211. col. 635-638.

En la segunda transición, que encabeza los sermones sobre la Circuncisión, se ofrecen una serie de disquisiciones que explican la razón de que Cristo fuese circuncidado no siendo pecador. Casi todo el texto de esta transición no es otra cosa que una copia de un fragmento del sermón III de la Circuncisión del Señor escrito por san Bernardo de Claraval (PL 183. col. 138). Sin embargo, sí pertenecen a Gil de Zamora y a su estilo de concebir las transiciones la fórmula inicial ya comentada, la invitación final y la fórmula de cierre.

En la transición a los sermones sobre la Epifanía Juan Gil toma como base el sermón I de Nicolás de Claraval sobre la Natividad del Señor (PL 184. cols. 827-829). Para la transición cuarta que encabeza los sermones de la Cuaresma no hemos encontrado su fuente, pero sospechamos que también debe haber sido tomada de algún sermón de otro autor, considerado seguramente una autoridad.

En contraste con la extensión de las transiciones comentadas apreciamos la brevedad de la quinta referente al Domingo de Ramos. Se nos ofrece simplemente la fórmula de transición: Iam ad sermones de Ramis Palmarum Ihesu preduce accedamus. Et primus sermo sit iste.

La transición a los sermones sobre la Resurrección es singular. Se anuncia la brevedad de los sermones porque el misterio de la Resurrección es tan grande que debe meditarse más que predicarse. Es una transición muy breve, aunque no reducida a la mera fórmula como la anterior.

Comentamos ahora las partes del sermón que las Artes praedicandi han transmitido teóricamente aplicándolas a la utilización que de ellas hace Juan Gil en sus sermones. Aportamos aquí las conclusiones generales de los siete sermones, pero añadimos ejemplos concretos de algunas partes del sermón VI (no 16 de la colección), el más breve de los editados.

\section{A) EL THEMA}

Lo primero que debe hacer el predicador es enunciar y localizar el tema, que va a ser la raíz y el germen de todo lo que venga a continuación. No en vano en algún tratado se compara el tema a la raíz del árbol del sermón: 
Praedicatio assimilatur arbori reali. Sicut enim arbor realis procedit ad truncum et truncus in principales ramos pululat et rami principales in alios multiplicantur, sic et praedicatio primo ex themate tanquam ex radice in truncum, i. praelocutionem uel prothema procedit, ac deinde ex praelocutione siue prothemate in principalem diuisionem thematis tanquam in ramos principales. Et rami principales thematis debent ulterius per secundarias diuisiones multiplicari i. e. in subdiuisiones uel subdistinctiones, et ultimo dilatari prout patet exemplum in arbore sequenti.

Pseudo Tomás de Aquino (incunable, fol. 9).

El tema debe poseer una serie de cualidades que enuncian los tratadistas. Entre ellas merecen destacarse las siguientes:

\section{1) Ut materie congruat}

Lo explica así Thomas Waleys (cap. 2):

Consuetudo communis est, et ab omnibus praedicatoribus moderni temporis merito approbata, ut praedicator in principio, quando incipit populi alloqui, thema suum proponat. Est autem thema dictum aliquod autenticum super quo intendet sermonem suum fundare. Vnde et sic accipiendum est ut materia congruat de qua praedicator principaliter loqui intendit. Dicitur enim thema in graeco quod nos uocamus materiam in latino. Vnde, nisi id quod accipitur pro themate contineat materiam sermonis, non thema propie dicitur.

Esta condición la cumplen todos los sermones que editamos y consiste simplemente en que el tema debe tener que ver con el asunto que se trata.

\section{2) Ut thema accipiatur ex Sacra Scriptura}

El tema debe ser un texto extraído de la sagrada escritura sin importar el libro con tal de que sea canónico. La razón de esta condición la expone Thomas Waleys (cap. 2):

Secundum est ut thema accipiatur ex sacra Scriptura. Licet autem scriptura beati Augustini et aliorum doctorum fidelium merito possit dici sacra et sancta, quatenus contineat catholicam ueritatem, tamen, antonomastie eloquendo quando de Sacra Scriptura absque addito facimus mentionem, semper intelligimus de illa scriptura que in canone Bibliae continetur. Et quia circa eius ueritatem non licet alicui fidelium dubitare, illa praestabit totius sermonis certissimum fundamentum.

En Gil de Zamora es frecuente la utilización del Antiguo Testamento, ya que da pie para ampliar el sermón por medio de prefiguraciones. 
3) Ut thema sit de textu Bibliae usitato nec mutato nec peruerso. (R. de Basevorn cap. 16):

A este respecto los tratadistas dan una serie variable de indicaciones que pueden resumirse en la idea fundamental de que el texto extraído de la Biblia no debe modificarse ni cambiarse. Las modificaciones que puedan hacerse han de ser mínimas y en ningún momento deben dejar el sentido del texto incompleto. Respecto al término usitato es importante que el texto del tema contenga palabras usuales para que el predicador, ayudado de una buena concordancia, pueda dilatar su sermón a voluntad. Otro dato importante es la longitud del tema. En los sermones de Juan Gil es variable, de dos palabras a frases más complejas.

\section{4) Localización del tema}

La localización del tema ha de ser lo más precisa posible indicando el libro de la Biblia y su capítulo. Un caso especial lo supone la localización de los salmos según se desprende del siguiente pasaje de Thomas Waleys (cap. 2):

Septimum documentum pertinet ad modum allegandi thema sicut et auctoritates alias. Et quantum ad hoc sciendum quod in allegatione thematis consueuit designari tam liber Sacrae Scripturae unde sumitur thema quam et ipsum capitulum, puta Mattaei uel Lucae tali aut tali capitulo, nisi forsan thema accipiatur de aliquo psalmo. Tunc enim quandoque signatur ipse psalmus et dicitur: Psalmus XL uel XXX, uel aliquo alio modo simili. Aliqui tunc ommitunt signationem talem, et solum dicunt: Istud habetur in Psalterio, et ratio quia psalmi sunt communiter satis noti.

Precisamente a este grupo de los que no consignan el número del salmo pertenece Gil de Zamora. La localización de sus temas se hace de dos maneras: colocando al lado del tema el libro y el capítulo o introduciendo la localización mediante la fórmula levemente variable de: Verba proposita scripta sunt...

En el conjunto de la colección de sermones el tema aparece en muy contadas ocasiones sin localización.

A modo de ejemplo este es el tema del sermón VI (no 16) (fol. 49va):

Flores apparuerunt in terra nostra. Tempus putationis aduenit. Verba proposita sunt uerba Salomonis scripta in Cant. II c.

\section{B) LA INTRODUCTIO THEMATIS}

Los sermones de nuestro autor no contienen ni oración inicial ni protema. A continuación de la enunciación y localización del tema se procede a una breve introducción del tema. El fin de la misma es desentrañar el sentido del tema, probando la verdad o la utilidad del mismo, o bien aplicándolo a la festividad que se celebra. En esta introducción no suele faltar la expresión de la persona que ha dicho las palabras 
del tema propuesto. La introducción del tema puede basarse en un razonamiento (sermón I), una analogía (sermón II), una prefiguración contenida en el Antiguo Testamento (sermón III), una narración (sermón IV), una aplicación a los tiempos de la Iglesia (sermones V y VI) o una comparación de tierra y cielo (sermón VII). La introducción suele cerrarse con la cita completa del tema.

El sermón VI ofrece esta introductio thematis (fol. 49va):

Et sub methaphora florum reducunt nobis ad memoriam sacramentum Dominice Passionis in eo quod premittitur flores apparuerunt et cetera. Quanto magis accedit Christi Passio tanto maior debet esse fidelium deuotio et animarum purificatio. Etiam quia Passio Ihesu Christi iam incipit appropinquare, iam incipit rutilare, idcirco Spiritus Sanctus, ut ad ipsam recipiendam conetur se ipsum quilibet preparare, dicit: Flores apparuerunt in terra et cetera.

La introducción del tema desliga a este de su contexto bíblico y le aplica un sentido metafórico, adecuando el tema a la Pasión del Señor y su preparación. Se termina la breve introducción con el enunciado del tema completo expresando también que la persona que pronuncia estas palabras es el Espíritu Santo.

\section{C) LA DIVISIO}

Tras la cita del tema que cierra la introducción aparece una frase alusiva al mundo terrestre laico y a sus costumbres, a partir de la cual comienza la división, que se realiza como solución o como oposición a esta frase alusiva del mundo mortal. La división suele introducirse con una fórmula mínima variable: Et secundum hec predicta Deus Pater in uerbis propositis duo facit... o Et contra hec predicta.... en caso de oposición. La división suele expresarse de forma paralela introduciendo cada miembro con primo, secundo o tertio dependiendo del número de miembros que compongan la división. A esta primera división le sigue generalmente una matización o ampliación de la misma que puede considerarse una segunda división superpuesta que completará el sentido. Esto puede observarse en la afirmaciones de Thomas Waleys (cap. 6):

Post introductionem thematis statim secundum consuetudinem modernam, sequitur diuisio eius. Diuidit enim ipsum praedicator in duo uel tria [uel quattuor; in quattuor uero raro, sed in duo uel tria] communiter. Et forsitan praedicator non erit contentus una diuisione thematis simplicis, sed faciat unam diuisionem duplicatam uel triplicatam, uel duas aut tres diuisiones. Una tamen praesupponit aliam, et posterior diuisio determinat priorem uel sensum eius complet ac perficit, uel forsan solus ornatus est diuisionis prioris. V.g accepi forsan thema istud, de Aduentu Domini: Hora est iam nos de somno surgere. Postquam autem ipsum introduxi, 
dico sic: Apostolus in his uerbis tria facit, quia excitat, suscitat et incitat. Excitat negligentes ut considerent, suscitat dormientes ut uigilent, incitat torpescentes ut [se] praeparent. Primum notatur cum dicitur: Hora est iam, secundum cum dicitur: de somno, tertium cum dicitur: nos surgere. Vides in [isto] modo diuidendi, post tria membra diuisionis primo accepta, adduntur alia tria quae correspondent tribus partibus thematis sicut et tria membra prima, et membra secundo posita complent membra primo posita.

A partir de la segunda división se hace una confirmación de los miembros de la división con los miembros que ofrece la sintaxis del tema, mediante diferentes fórmulas. Por lo general a esta confirmación sigue una nueva cita del tema precedida por un igitur de carácter sumativo.

La diuisio del sermón VI es esta (49va-49vb):

Quando uexillum imperatoris in castris incipit apparere, incipiunt milites caput erigere seque ad bellum disponere. Et secundum hec predicta Spiritus Sanctus ad nostram instructionem in uerbis propositis duo facit:

Primo namque proponit coram nostris oculis sacramentum Dominice Passionis. Secundario nos hortatur ad resecationem totius ambitionis. Sacramentum Dominice Passionis innuitur in florum apparitione, ideo premittit: Flores apparuerunt in terra nostra. Resecatio totius ambitionis innuitur in congruenti putatione. Sicut enim a uite uel ab arbore quod est superfluum resecatur et quod est utile reseruatur, ita inminente Christi Passione debent uitia resecari et quod est uirtus diligentissime reseruari. Et ideo concludit: tempus putationis aduenit. Dicit igitur: Flores apparuerunt et cetera.

La división se introduce por la consideración de la actitud de los soldados cuando ven venir la enseña de su emperador. Sigue la fórmula que introduce la división propiamente dicha: Et secundum hec predicta Spiritus Sanctus ad nostram instructionem in uerbis propositis duo facit. La división consta de dos miembros, que se amplían de diverso modo. El primer miembro es ampliado con una frase y confirmado por la primera cláusula del tema. El segundo miembro es ampliado por una frase, pero seguido de una similitudo de carácter vegetal que aclara su sentido. A continuación es confirmado con la enunciación de la segunda cláusula del tema. El hecho de que el segundo miembro esté más ampliado se debe a que la declaración de las partes del sermón va a tomar como base la identificación de la flor con la Pasión de Cristo, que pertenece al primer miembro de la división. La división concluye con la enunciación del tema completo precedida de la fórmula: Dicit igitur. 


\section{D) LA DECLARATIO PARTIUM}

Tras la división aparece la declaración de las partes que estará en relación con el primer miembro de la sintaxis del tema (sermones I, III, V y VI) o con el tema completo (sermones II, IV y VII). La declaración de las partes se basa en una distinción que comienza con la exposición de las cualidades o tipos de algo que se desea distinguir, generalmente en tres miembros. Puede tratarse de las cualidades del mundo antes de la venida de Cristo (sermones I y II), de los tipos de alegría del mundo (sermón III), de los tipos de mirada (sermón IV), de los tipos de hombres que se lamentan en el mundo (sermón V), de las cualidades de las flores (sermón VI) o de las cualidades de las cosas del mundo (sermón VII). Estas cualidades o tipos de ámbito material se aplican a lo divino mediante la fórmula: Et secundum hec tria... Se suelen distinguir, pues, tres cualidades o tipos materiales a los que se aplican soluciones espirituales. La correspondencias entre unas y otras serán el comienzo y punto de partida de cada una de las partes del sermón (tres por lo general).

Esta es la declaratio partium del sermón VI (fol. 49vb):

In floribus tria possumus considerare per que Passionem Christi floribus possumus comparare. Est enim reperire in floribus uiuacissimum ruborem, intensissimum candorem, suauissimum odorem. Et secundum hec predicta, in Deo Filio Ihesu Christo est reperire Passionis ruborem, innocentie candorem, omnium uirtutum et gratiarum odorem. Totus fuit in corpore rubricatus. Totus in anima candidatus. Totus fuit intus et extra donis, gratiis et uirtutibus priuilegiatus mirabiliter et dotatus.

En la declaración de las partes el predicador se dedica a ampliar la metáfora flor=Pasión. Comienza distinguiendo tres propiedades naturales en las flores que expone paralelísticamente:

-uiuacissimum ruborem

-intensissimum candorem

-suauissimum odorem

A cada propiedad de las flores se hace corresponder una característica de la Pasión del Señor, empleando similar vocabulario y una forma de igual modo paralela: -passionis ruborem

-innocentie candorem

-omnium uirtutum et gratiarum odorem

Estas atribuciones se amplían aún más para que queden claras. Se utiliza igualmente un vocabulario parecido y una disposición similar, sabiendo que el tercer miembro siempre es el más desarrollado.

-Totus fuit in corpore rubricatus

- Totus in anima candidatus

-Totus fuit intus et extra donis gratiis er uirtutibus priuilegiatus mirabiliter et dotatus. 


\section{E) DiLATATIO}

Al encabezamiento de cada una de las partes del sermón le sigue una autoridad confirmativa de la Biblia que a su vez se comentará por diversos procedimientos y a la que se unirán autoridades de doctores de la Iglesia y Santos Padres.

Los procedimientos de expansión de un sermón ${ }^{17}$ utilizados por Gil de Zamora son los siguientes:

1) El uso de las autoridades biblicas, patristicas y filosóficas.

Las autoridades son una de las técnicas más utilizadas por Gil de Zamora. Su utilización es frecuentísima y casi podemos decir que Gil de Zamora sólo ha sido original en la concepción de la estructura del sermón ya que el resto se rellena con autoridades bíblicas y de la Iglesia.

La suprema autoridad es la Biblia, de ella se ha escogido el tema del sermón y con ella se confirman cada una de las partes del sermón. Sus textos no deben ser alterados frente a los de los Padres de la Iglesia y otros Doctores o predicadores que Juan Gil utiliza en muchas ocasiones parafraseándolos o tomando sólo las partes que le interesan suprimiendo frases o pasajes de la fuente. En la Biblia se sigue la versión oficial, no obstante hay libros para mejorar la recensión oficial y estos libros han sido escritos sobre todo por integrantes de las órdenes mendicantes. El mismo Gil de Zamora escribió una obra en este sentido, el Prosologion seu tractatus de accentu et de dubilibus Bibliae.

A estas autoridades bíblicas las apoyan, profundizando en su sentido y completando detalles, las autoridades de los Padres y Doctores de la Iglesia, además de otros autores de sermones.

Juan Gil de Zamora se apoya en autoridades que le proporcionan citas de tratados teológicos como Ricardo de San Víctor (De Trinitate) o san Agustín (Tractatus in Iohannem). También emplea fuentes de comentarios de textos bíblicos como las Enarrationes in psalmos de san Agustín y quizá el Comentario al Cantar de los cantares de san Gregorio de Elvira. Otras autoridades, entre las muchas de las que se da cuenta en la edición de los siete sermones, son san Anselmo de Canterbury (Liber orationum et meditationum (en algunas ocasiones bajo el nombre de Anselmo está en realidad Auctor incertus. Anselmus Cantuariensis? Meditationum liber unus (PL 40)), Adamo de Persenia, las Vitae Patrum o san Isidoro. Pero lo más abundante es el empleo de fragmentos de sermones de otros autores como san Bernardo de Claraval y Nicolás de Claraval (los más citados), san Agustín, el Papa León o san Pedro Damián.

17 H. CAPLAN en su artículo "Classical rhetoric and the medieval theory of preaching", Classical Philology 28, (1933), pp. 88-90, recoge los procedimientos de expansión de un sermón recopilados a partir de las Artes praedicandi que él consultó. En la Edad Media circulaban pequeños tratados al respecto, el más famoso de los cuales es el de Ricardo de Thetford, incluido también como $3^{\text {a }}$ parte del Ars concionandi del Pseudo-Buenaventura. 
Estos fragmentos de sermones ajenos son los que le sirven para amplificar los suyos, poniendo él la estructura y la disposición y tomando prestados la mayor parte de los contenidos.

Sería complejo incluir aquí las fuentes utilizadas tal como nosotros las poseemos en nuestras ediciones para compararlas con lo que Juan Gil tomó de ellas. Baste un ejemplo para observar que a veces la cita no es literal o toma sólo parte de su fuente y se añaden datos nuevos. Una comparación del texto de la Patrología Latina 183, 93 y del texto del sermón III que recoge la cita de san Bernardo In vigilia Nativitatis. Sermo II puede ser ilustrativa:

\begin{tabular}{|c|c|}
\hline SERMO III (fol. 27ra-27rb) & Patrologia Latina i 83, 93 \\
\hline $\begin{array}{l}\text { Exultare fecimus angelos quando conuer- } \\
\text { si sumus ad penitentiam. Proficiamus et } \\
\text { festinemus complere de nobis eorum leti- } \\
\text { tiam. Exultauerunt cum nos ad peniten- } \\
\text { tiam uenimus, tanquam super his quos ab } \\
\text { ipsa porta inferi cernerent reuocari. Quid } \\
\text { nec erit si ab ipsa paradisi ianua uideant } \\
\text { reuerti et abire retrorsum eos qui iam pe- } \\
\text { dem alterum habuerint in paradiso? Absque } \\
\text { dubio constristantur soli angeli sed etiam } \\
\text { ipse angelorum Creator nos desiderat, expe- } \\
\text { tit et expectat. Curramus ergo desideriis et } \\
\text { profectu uirtutum magno affectu in celum } \\
\text { clamantes, ut ille pastor bonus qui pro nobis } \\
\text { animam suam posuit, ad ouile glorie merito } \\
\text { sue gratie nos perducat. }\end{array}$ & $\begin{array}{l}\text { Exsultare fecimus angelos, quando conver- } \\
\text { si sumus ad paenitentiam; proficiamus et } \\
\text { festinemus complere de nobis eorum laeti- } \\
\text { tiam. Vae tibi, quicumque es qui deliberas } \\
\text { redire ad lutum, reverti ad vomitum! Putas- } \\
\text { ne placatos habebis in iudicio, quos tanto } \\
\text { et tam sperato privare vis gaudio? Exsulta- } \\
\text { verunt cum nos ad paenitentiam venimus, } \\
\text { tanquam super his quos ab ipsa inferi porta } \\
\text { cernerent revocari. Quid nunc erit si ab ipsa } \\
\text { inferi ianua reverti viderint et abire retror- } \\
\text { sum eos qui iam pedem alterum habent } \\
\text { in paradiso? nam etsi corpora inferius, sed } \\
\text { corda sursum. Currite, fratres, currite: non } \\
\text { soli angeli sed ipse angelorum vos Creator } \\
\text { expectat. Nuptiae paratae sunt sed nondum } \\
\text { plana domus, adhuc expectantur, de quibus } \\
\text { nuptiae impleantur, expectat vos Pater et } \\
\text { desiderat. }\end{array}$ \\
\hline
\end{tabular}

La única autoridad filosófica pagana que hemos registrado en los sermones editados es la de Séneca al final del sermón VII. La autoridad de Séneca no se trae a colación como filósofo moral, como era habitual en los textos cristianos, sino como autoridad "científica" en un contexto que tiene por misión comparar la pequeñez de la tierra con la inmensidad del cielo. 


\begin{tabular}{|c|c|}
\hline SERMO VII (fol. 56va) & $\begin{array}{c}\text { SÉNeca } \\
\text { (Naturales Quaestiones, Praef. I3) }\end{array}$ \\
\hline $\begin{array}{l}\text { Et tanta est latitudo celi et eterni palatii } \\
\text { quod tota terra non nisi punctus est respectu } \\
\text { celi. Propter quod dicit Seneca quod: paucis } \\
\text { diebus posset nauis ab Hispania usque in } \\
\text { Indiam nauibare, velocissimus uero pla- } \\
\text { neta ut saturnus uix potest annis XXX per- } \\
\text { ficere circulum firmamentum. }\end{array}$ & $\begin{array}{l}\text { Tunc contemnit domicilii prioris angustias. } \\
\text { Quantum est enim quod ab ultimis litori- } \\
\text { bus Hispania usque ad Indos iacet? Paucis- } \\
\text { simorum dierum spatium, si nauem suus } \\
\text { ferat uentus. At illa regio celestis per triginta } \\
\text { annos uelocissimo sideri uiam praestat nu- } \\
\text { squam resistenti sed aequaliter cito. }\end{array}$ \\
\hline
\end{tabular}

\section{2) Explicación de la Escritura}

Las autoridades bíblicas, sobre todo las confirmativas, son explicadas minuciosamente por Gil de Zamora. La explicación suele hacerse a partir de consideraciones previamente establecidas que se correlacionan con las cláusulas de las autoridades. Otro tipo de explicación es la metafórica. A un texto del AT o del NT se le ańaden apreciaciones e interpretaciones según convenga por medio de scilicet, id est o supple.

\section{3) Uso de comparaciones, metáforas y ejemplos.}

El uso de las similitudines es muy amplio afectando al ámbito de la guerra, de la naturaleza, de los animales y de la corte. Puede aparecer en la introducción del tema, pero su papel fundamental está en las distintas partes del sermón con una función determinada. Su estructura más común es la de sicut...ita...

La metáfora también está presente en los sermones, concretamente la metáfora de la flor identificada con la cruz de Cristo es la columna vertebral del sermón VI.

En los sermones editados no aparecen más que dos exempla: uno tomado de las Vitae Patrum (De Vitis patrum liber V. Libellus tertius (de compunctione) 14. PL 73. col. 862) y otro sin localización. Lo importante de estos es su colocación en un mismo sermón (el V) y en lugares similares, al final de la segunda parte uno y al final de la tercera el otro, cerrando el sermón.

\section{4) La prefiguración}

La prefiguración es un medio muy utilizado por los predicadores. Es muy habitual que se ocupe de la figura de la Virgen y ejemplo de ello tenemos en el I y II de los sermones editados. En el sermón I la idea de la Virgen prefigurada en la zarza, el báculo, la estrella y el vellón está tomada de las Homilías de san Bernardo sobre el versículo que comienza "Missus est...", más conocido por De Laudibus Virginis.

\section{5) La interpretatio}

En Gil de Zamora encontramos el recurso de la interpretatio o traducción de nombres hebreos, que añaden nuevos matices e incluso vertebran el sermón, 
como es el caso del sermón III donde es muy importante que Isaac signifique "risa". Ejemplos de interpretatio los tenemos en el sermón I (Sara=uelamen), en el II (Noemi=consolata y Obeth=seruitus) y en el VI donde se traducen los nombres de María contenidos en el libro De ortu et obitu Patrum de san Isidoro (PL 83. col. 148). Todo esto concuerda con lo que dice el Ars concionandi (34):

Cum autem per interpretationem uolumus dilatare, respiciendum est ad diuersas interpretationes, et hoc uel secundum Hieronymum uel secundum Isidorum et alios;

Como ejemplo concreto comentamos brevemente el procedimiento de expansión que utiliza Juan Gil en el segundo miembro del sermón VI (fol. 50ra-50va).

Secundario crux Christi dicitur flos propter innocentem candorem, quia sicut flos sine corruptione arboris oritur, intus et extra habet munditiam candoris, ita Ihesus Christus Dei Filius natus est sine corruptione de Virgine et sine sui labe positus in cruce. Ipse enim solus est qui peccatum non fecit, nec inuentus est dolus in ore eius. Et propter hoc de ipso dicit anima sancta Cant. I : Ecce tu pulcher es, dilecti mi, et decorus. Lectulus noster floridus. Pulcher fuit Dei Filius exterius in corpore. Decorus interius in mente. Et quia pulcher fuit et decorus, ideo lectulus suus floridus, quia ipse nec corruptione aliqua corruptus, nec uterus matris eius pudore euacuatus. Vnde Isaias XI: Egredietur uirga de radice Iesse et flos de radice eius ascendet. Virga fuit Virgo Maria. Flos uero Ihesus Filius eius. Illa uirga fuit tenuis et delicata de Iesse quod interpretatur incendium amoris. Egressa fuit mater saluatoris, quia Spiritus Sanctus qui in eius corde ardebat in eius corde mirabilia faciebat secundum Hugonem. Et propter hoc dicit Isidorus in libro de Nouo Testamento: Maria que interpretatur domina siue illuminatrix clara extirpe Dauid et uirga Iesse, ortus conclusus, fons signatus, mater Domini, templum Dei uiui, sacrarium Spiritus Sancti. Igitur quia Virgo Maria uirga fuit mundissima et Filius eius fuit flos pulcerrimus et palma pulcerrima idcirco pueri tanquam puri cum ramis et floribus hodierna die sibi processionaliter occurrerunt. Vnde cantat Ecclesia quod pueri hebreorum tolentes ramos oliuarum cum floribus et palmis obuiauerunt domino, cantantes et dicentes: Osanna in excelsis. Quisquis ergo Christo desiderat obuiare sit puer, id est purus, sit nazarenus, id est floridus. Vnde beatus Bernhardus in sermonibus: Amat florigeram patriam flos de radice Iesse et libenter inter lilia pascitur flos campi et lilium conuallium. Teque florem reputat Deus et bene sibi complacet in te. Si tibi nec honeste conuersationis decor, nec honeste conuersationis fragrantia nec intentio deest future retributionis.

La segunda parte del sermón comienza con una fórmula aplicada a la segunda cualidad que se había establecido en la declaración de las partes: Secundario crux 
Christi dicitur flos propter innocentem candorem. Continúa con una similitudo entre la belleza de la pureza de la flor y la de Cristo, que nace sin tacha de la Virgen. Se añade para ampliar la autoridad del Cantar de los cantares (Cant. 1,15), que incluye la palabra pulcher. Esta autoridad se explica y se hila con la autoridad de Isaías, referida al vástago de Jesé, donde se identifican uirga con María y flos con Jesús. Se amplifica ahora el sermón deteniéndose en María como uirga acudiendo a la interpretatio del nombre de Jesé, a la autoridad de Hugo de San Víctor (Hugo de S. Victore, De B. Mariae Virginitate. PL 176. col. 872), muy socorrida en los sermones de Juan Gil, y a la interpretatio del nombre de María según san Isidoro (De ortu et obitu patrum, cap. 66,1). La atribución de María=vástago, Jesús=flor y palma le lleva a hacer referencia a la procesión del Domingo de Ramos donde los niños como puros que son (se juega con el latín pueri=niños, puri=puros) van con ramos y flores al encuentro del Señor. Todo esto tiene ya relación directa con la fiesta que se celebra y Juan Gil no puede dejar escapar esta oportunidad para aleccionar a los fieles. Se recoge el juego puer-purus y la referencia de Nazarenus=floridus (interpretatio que se ha hecho en la transición a la Navidad, y que concuerda con la autoridad del Cantar de los cantares que se ha aducido recientemente). Esta segunda parte termina con la autoridad de san Bernardo (In Anuntiatione B. V. Mariae. Sermo III. PL 183. col. 396).

\section{F) Conclusión}

Al final del desarrollo del tercer miembro se termina con alguna palabra que haga alusión a la gloria del cielo para desearnos su consecución con la fórmula más o menos variable: ad quod nos perducat ....

Observando los explicit de cada sermón constatamos siempre este final orientado a la vida futura y unido a la fórmula conclusiva de la Trinidad, sin embargo hay dos sermones en toda la obra ( n $^{\circ} 5$ y 6 ) que no terminan así, sino aludiendo a la figura de san Francisco de Asís y a su Leyenda.

Podemos concluir, siempre dentro de la provisionalidad que da el haber analizado tan solo siete de los sermones del Liber sermonum, diciendo que Juan Gil de Zamora como predicador se atiene a los procedimientos retóricos codificados en las Artes praedicandi siendo su labor de predicador la de un compilador no demasiado original. 
